\title{
Survival of the copepod Acartia tonsa following egg exposure to near anoxia and to sulfide at different $\mathrm{pH}$ values
}

\author{
Marion Invidia, Sandra Sei, Gessica Gorbi* \\ Department of Environmental Science, University of Parma, Parco Area delle Scienze 11/A, 43100 Parma, Italy
}

\begin{abstract}
The impact of near anoxia $\left(1.78 \times 10^{-3}\right.$ to $\left.3.56 \times 10^{-3} \mathrm{mmolO}_{2} \mathrm{l}^{-1}\right)$ and anoxia/sulfide $\left(\sim 1 \mathrm{mmol} \mathrm{l}^{-1}\right)$ on hatching and viability of eggs of the planktonic copepod Acartia tonsa was evaluated. Since the equilibrium concentration of the sulfide species is influenced by $\mathrm{pH}$ and the different species have different capacities to enter cells, the impact of sulfide was analyzed at $\mathrm{pH} 8.2$ and 6.5. The consequences of egg exposure for growth and survival of the hatched organisms were also studied. Subitaneous eggs, spawned by laboratory-reared organisms, were incubated in near anoxia or anoxia/sulfide for different periods $(1,4,15$ and $32 \mathrm{~d})$ and then transferred to normoxic conditions. Short exposure to near anoxia or anoxia/sulfide did not affect egg viability and subsequent growth and survival. Exposure times $\geq 15 \mathrm{~d}$ caused significant declines in hatching and strong reductions in life expectancy. No significant differences between the effects of near anoxia and anoxia/sulfide (at both $\mathrm{pHs}$ ) were observed following incubation for $15 \mathrm{~d}$. After $32 \mathrm{~d}$ incubation, the hatching success of eggs exposed to anoxia/sulfide at $\mathrm{pH} 8.2$ was significantly higher than that of eggs exposed to near anoxia or to anoxia/sulfide at $\mathrm{pH} 6.5$, and life expectancy was also less reduced. The results indicate that long exposure of eggs to anoxia/sulfide is less detrimental to A. tonsa than near anoxia alone when the $\mathrm{pH}$ is in the range of natural seawater (7.9 to 8.3). It seems to be more detrimental when $\mathrm{pH}$ is as low as that reached in pore waters (6.0 to 6.5$)$.
\end{abstract}

KEY WORDS: Near anoxia $\cdot$ Sulfide $\cdot \mathrm{pH} \cdot$ Acartia tonsa

\section{INTRODUCTION}

During the last decades nutrient over-enrichment has affected many shallow coastal and estuarine areas around the world, bringing large-scale consequences such as an increasing and spreading occurrence of hypoxic and anoxic waters (Diaz \& Rosenberg 1995, Nixon 1995, Paerl 1997, Diaz 2001, Rabalais \& Turner 2001). Oxygen depletion is frequently coupled with the production of hydrogen sulfide, which is toxic to most aerobic organisms. In aqueous solution, the equilibrium concentration of the different sulfide species varies with $\mathrm{pH}$. In natural seawater, where $\mathrm{pH}$ ranges from 7.9 to 8.3 , the predominant species is the hydrosulfide anion $\left(\mathrm{HS}^{-}\right)$. In pore water, where $\mathrm{pH}$ can be as low as 6.0 to 6.5 , the neutral molecular $\mathrm{H}_{2} \mathrm{~S}$ may prevail
(Vismann 1996, Wang \& Chapman 1999). While $\mathrm{H}_{2} \mathrm{~S}$ freely crosses membranes, the $\mathrm{HS}^{-}$anion may be electrically excluded (Bagarinao 1992, Wang \& Chapman 1999). It has been shown that total sulfide toxicity is modulated by $\mathrm{pH}$ and increases with decreasing $\mathrm{pH}$ (Powell \& Somero 1986, Vismann 1996). According to Bagarinao (1992), however, the $\mathrm{HS}^{-}$anion also seems to contribute to toxicity at high sulfide concentrations.

Hypoxic $\left(<0.089 \mathrm{mmol} \mathrm{l}^{-1}\right.$ dissolved oxygen, according to Diaz \& Rosenberg 1995), anoxic, and sulfidic conditions occur more frequently in sediments and bottom waters. Numerous studies of the impact of these stressors on biota have therefore focused on benthic fauna (Pihl et al. 1991, Nilsson \& Rosenberg 1994, Gamenick et al. 1996, Vistisen \& Vismann 1997, Vopel et al. 1998). Many planktonic species release 
subitaneous or diapause eggs freely into the water column. These eggs tend to sink and so can spend hours to years in the seabed before hatching (Marcus \& Boero 1998); they can, hence, be exposed to hypoxia, anoxia and/or sulfide. Thus, these stress conditions, even if occurring at the water/sediment interface, may affect population dynamics of planktonic species. Many of the studies carried out on planktonic species (Uye \& Fleminger 1976, Ambler 1985, Lutz et al. 1992, 1994, Roman et al. 1993, Marcus \& Lutz 1994, Stalder \& Marcus 1997) have dealt with Acartia tonsa, a calanoid copepod very common in many lagoons and estuarine areas. Lutz et al. (1994) reported that the eggs of this species stop hatching at oxygen concentrations lower than $3.12 \times$ $10^{-3} \mathrm{mmol} \mathrm{l}^{-1}$, but are not killed since they resume hatching when transferred to normoxic seawater. The results obtained by various authors (Uye \& Fleminger 1976, Ambler 1985, Lutz et al. 1992, 1994, Roman et al. 1993, Marcus \& Lutz 1994) differ slightly in regard to the concentration of oxygen that induces quiescence and the maximum survival times for eggs exposed to low oxygen concentrations. The impact of anoxia and sulfide (at $\mathrm{pH}$ 8.2) on egg viability of planktonic copepods under laboratory conditions has been studied only by Marcus et al. (1997). The authors exposed the eggs of the calanoids A. tonsa, Labidocera aestiva and Centropages hamatus to anoxia and anoxia/sulfide and concluded that there is no significant difference in viability between eggs exposed to anoxia/sulfide and those exposed to anoxia alone. All these studies only took hatching success into account, and no data are available on the development and life expectancy of the individuals hatched from eggs exposed to these stress conditions. But, according to Hagerman (1998), 'to be alive after exposure to hypoxia or sulfide is not the same as surviving', since processes acting during the recovery phase to restore the fuel resources and reoxidise metabolites (oxygen debt) are also important. As a consequence, the cost of the recovery borne during the embryonic stage might affect growth and survival of subsequent developmental stages.

The aim of the present study was to assess hatching and viability of Acartia tonsa eggs exposed to near anoxia and sulfide for different times, and to evaluate the consequences of egg exposure on growth and survival at the subsequent developmental stages. The experiments were performed at high concentrations of dissolved sulfide $\left(\sim 1 \mathrm{mmol}^{-1}\right)$ to evaluate the effects of extreme conditions. This choice was made on the basis of the highest sulfide concentrations reported in the literature for highly eutrophic environments (Bagarinao 1992, Bartoli et al. 1996, Giordani et al. 1996) and detected in water column and at sediment superficial layers. Considering that the equilibrium concentration of the sulfide species is influenced by $\mathrm{pH}$, and that the different chemical species may have different capacities to enter cells, the experiments were carried out at 2 different pHs: 8.2 and 6.5.

\section{MATERIALS AND METHODS}

Sampling and maintenance cultures. Acartia tonsa eggs used in the experiments came from laboratory cultures. To set up cultures, zooplankton samples were originally collected in the Venice lagoon (North Adriatic Sea, Italy) using a $50 \mu \mathrm{m}$ mesh plankton net. The samples were diluted in a $5 \mathrm{l}$ tank immediately after collection and transported to the laboratory within $4 \mathrm{~h}$.

Adults (females and males) of Acartia tonsa were sorted under a dissecting microscope and transferred into aquaria $(21 \times 20 \times 25$ [height] $\mathrm{cm})$ containing natural seawater ( $\mathrm{S}=30$ to $32 \%$; $\mathrm{pH}=8.2 \pm 0.1$ ) filtered through a $0.45 \mu \mathrm{m}$ mixed cellulose ester filter. The aquaria were maintained in a room with constant temperature at $20 \pm 1^{\circ} \mathrm{C}$ and a $14 \mathrm{~h}$ light: $10 \mathrm{~h}$ dark cycle. The cultures were fed a mixture of 3 algal species: Isochrysis galbana (CCAP 927/1), Tetraselmis suecica (CCAP 66/22A) and Rhinomonas reticulata (CCAP 995/2).

Algae were cultured in the laboratory in artificial medium according to APHA, AWWA, WPCF (1989). The original recipe was modified: $\mathrm{CoCl}_{2}\left(0.01 \mathrm{mg} \mathrm{l}^{-1}\right)$ was added and the amounts of $\mathrm{NaNO}_{3}$ and $\mathrm{K}_{2} \mathrm{HPO}_{4}$ were increased to obtain final concentrations of $\mathrm{P}$ and $\mathrm{N}$ more appropriate for the algae we were cultivating, i.e. $12.6 \mathrm{mg} \mathrm{N}^{-1}, 1.12 \mathrm{mg} \mathrm{P}^{-1}, \mathrm{~N}: \mathrm{P}=11: 3$. The cultures were maintained in a room with constant temperature at $20 \pm 1^{\circ} \mathrm{C}$. Cool, white, fluorescent lights provided 3000 lux illumination on a $12 \mathrm{~h}$ light: $12 \mathrm{~h}$ dark cycle.

Experimental procedures. To guarantee the constant composition of the medium, all the experiments were carried out in artificial seawater (APHA, AWWA, WPCF 1989, modified in the content of $\mathrm{NaCl}$ to obtain a salinity of $30 \%$ ).

The water was deoxygenated by bubbling it for about $2 \mathrm{~h}$ with nitrogen gas previously washed using Dreschel bottles containing a mixture of 1 part pyrogallol solution $(25 \%)$ and 5 parts caustic liquid potassium (1.52 to 1.54 density). The $\mathrm{pH}$ was then measured and adjusted to 8.2 with diluted $\mathrm{HCl}$. Screw-capped vials $(25 \mathrm{ml})$ were carefully filled with the water to avoid trapping any gas bubbles. A suitable number of vials (from 4 to 10 for each exposure time, depending on the number of spawned eggs) was used for the incubation of the eggs. Initial and final (at the end of the incubation period) oxygen concentrations were determined by the micro-Winkler 
method (APHA, AWWA, WPCF 1989). At the low values obtained (dissolved oxygen $<3.56 \times 10^{-3} \mathrm{mmol} \mathrm{l}^{-1}$, from now on referred to as 'near anoxia'), oxygen determination required the use of the entire volume of water in a single vial, causing the loss of the incubated eggs. As preliminary tests (data not reported) indicated that even after $32 \mathrm{~d}$ of incubation there were no significant differences in the oxygen concentrations between vials with and without eggs, oxygen determination in the experiments was made on vials without eggs (6 vials per experiment).

Sulfide stock solution $(\sim 0.1 \mathrm{M})$ was prepared as follows: $2.1 \mathrm{~g}$ anhydrous $\mathrm{Na}_{2} \mathrm{CO}_{3}$ were added to $100 \mathrm{ml}$ bidistilled water, the solution was boiled for $10 \mathrm{~min}$ to remove oxygen, the hot solution was added to about $2.4 \mathrm{~g} \mathrm{Na}_{2} \mathrm{~S} \times 7-9 \mathrm{H}_{2} \mathrm{O}$ (only white crystals were used) and mixed well. Stock solution was dispensed into screw-capped glass vials with minimum headspace. Sulfide concentration of the stock solution was determined according to the method of Cline (1969). The vials were stored at room temperature in the dark.

To obtain the required sulfidic conditions $(\sim 1 \mathrm{mmol}$ $\mathrm{l}^{-1}$ of total sulfide), a suitable aliquot of sulfide stock solution was added to artificial water deoxygenated as described above. The $\mathrm{pH}$ was then readjusted to 8.2 or 6.5 with diluted $\mathrm{HCl}$, and screw-capped vials $(25 \mathrm{ml})$ were filled for the treatment of the eggs. Before and after filling the vials, 2 subsamples of water were taken to determine the initial sulfide concentration (Cline 1969). At the end of the incubation period, sulfide concentration was determined on aliquots taken from the vials used for the egg incubation.

The preparation of the near-anoxic and sulfidic water and the filling of the vials were done inside a modified atmosphere $\left(\sim 100 \% \mathrm{~N}_{2}\right)$ chamber. Before and during the incubation, the vials filled with near-anoxic water were kept in an Anaerojar (HP11, Oxoid) filled with nitrogen gas, to avoid increases in oxygen concentration.

In all experiments the vials were prepared $24 \mathrm{~h}$ before the introduction of the eggs. The addition of high sulfide amounts to near-anoxic water brought the system (vial) to anoxia (as determined according to the method of Mor \& Beccaria 1971) within the $24 \mathrm{~h}$. From now on, the term 'sulfide' will be used to indicate this treatment.

Five days before the beginning of the experiments, about 20 females and 20 males were isolated from 15 or $21 \mathrm{~d}$ old cohorts, transferred into a crystallizing dish containing $300 \mathrm{ml}$ natural seawater (NSW) and $300 \mathrm{ml}$ artificial seawater (ASW) and fed a mixture of the 3 algal species. About $15 \mathrm{~h}$ before the beginning of the experiments the organisms were distributed into 4 smaller crystallizing dishes containing $200 \mathrm{ml}$ ASW and fed. This procedure was used to avoid a drastic transfer of the adults from natural into artificial seawater, and to allow the spawning of the eggs in artificial seawater. The eggs spawned during the subsequent $15 \mathrm{~h}$ were collected under a dissecting microscope and transferred into 24 -well plates, 1 egg per well, containing $2.5 \mathrm{ml}$ normoxic ASW (controls) at $\mathrm{pH} 8.2$ or 6.5 , or into the vials (8 to 10 eggs per vial) containing near-anoxic or sulfidic seawater at $\mathrm{pH} 8.2$ or 6.5. The vials were incubated for $1,4,15$ or $32 \mathrm{~d}$ at a temperature of $20 \pm 1^{\circ} \mathrm{C}$ and a $14 \mathrm{~h}$ light: $10 \mathrm{~h}$ dark cycle. At the end of the incubation period the eggs were transferred to 24 -well plates containing normoxic ASW at pH 8.2.

The eggs were checked daily until hatching or degeneration. Since the nauplii were not able to reach the copepodid stage in the multi-well plates (data not reported), they were transferred into small crystallizing dishes containing $45 \mathrm{ml}$ ASW (3 nauplii per dish) just after hatching. The hatched individuals were fed a mixture of the algae Isochrysis galbana $\left(5 \times 10^{4}\right.$ cells $\left.\mathrm{ml}^{-1}\right)$ and Tetraselmis suecica $\left(1 \times 10^{4}\right.$ cells ml$\left.{ }^{-1}\right)$ and maintained at the same conditions of temperature and photoperiod as the bulk cultures. Water and algae were renewed once a week. Survivorship and the number of organisms at the different developmental stages (nauplius, copepodite and adult) were recorded daily till the cohorts died out. Females and males were placed together to allow egg fertilisation and spawning.

The experiments were repeated once or twice.

Data analysis. Each vial was considered as a replicate for hatch data analysis. Since the data were counts with a binary outcome (live/dead), a series of nonparametric tests was used to evaluate and compare the influence of the different conditions (normoxia, near anoxia, sulfide at $\mathrm{pH} 8.2$ and sulfide at $\mathrm{pH} 6.5$ ) and exposure times on hatching success. The JonckheereTerpstra trend test for ordered differences among classes (exposure time) and Kruskal-Wallis 1-way analysis of variance by ranks, followed by the comparison procedure described by Dunn (1964), were applied.

To evaluate and compare the influence on growth and survival, data from replicated experiments were pooled. Two kinds of survival curves were constructed: mortality pattern of hatched organisms over time and survivorship over the course of the entire life cycle, dividing development into 4 stages (egg, larval, i.e. nauplius, juvenile, i.e. copepodite and adult). The Kolmogorov-Smirnov nonparametric test was applied to compare survival curves over time and Survival-Life Table analysis by Wilcoxon (Gehan) nonparametric test was applied to compare survivorship during development (life expectancy). 


\section{RESULTS}

In near-anoxic vials, final oxygen concentrations ranged from $1.78 \times 10^{-3}$ to $3.56 \times 10^{-3} \mathrm{mmol} \mathrm{l}^{-1}$. Only during $32 \mathrm{~d}$ experiments were dissolved oxygen values slightly increased to between $4.02 \times 10^{-3}$ and $4.46 \times$ $10^{-3} \mathrm{mmol} \mathrm{\textrm {l } ^ { - 1 }}$. Initial sulfide concentrations ranged from 0.78 to $1.12 \mathrm{mmol} \mathrm{l}^{-1}$. The final concentrations showed a slight decrease with increasing incubation time. The lowest final value $\left(0.66 \mathrm{mmol} \mathrm{l}^{-1}\right)$ was observed after $32 \mathrm{~d}$ exposure. $\mathrm{pH}$ did not change in all experimental vials.

Vials containing a gas bubble at the end of the incubation period were not considered and some eggs were lost during the transfer to or from the vials. This caused variation in the vial and egg numbers among the experiments.

\section{Hatching success}

In normoxic conditions (control), hatching success ranged from 88 to $100 \%$, with the exception of 2 multiwell plates at $\mathrm{pH}$ 6.5, where it was $75 \%$ (Fig. 1). No hatching occurred during either near anoxia or sulfide treatment, irrespective of the exposure time and $\mathrm{pH}$ : the eggs resumed hatching only after transfer to normoxic seawater.

Eggs exposed to near anoxia resumed hatching within $48 \mathrm{~h}$. Incubation in near-anoxic conditions for 1 or $4 \mathrm{~d}$ did not significantly reduce the final hatching success (Fig. 1), which almost always reached 100\% after $1 \mathrm{~d}$ exposure and ranged from 67 to $100 \%$ after $4 \mathrm{~d}$. Increasing the incubation time reduced hatching
(Jonckheere-Terpstra trend test; $\mathrm{p}<0.001$ ). The hatching success of the eggs incubated for $15 \mathrm{~d}$ showed the highest variability, ranging from 0 to $100 \%$, and was significantly ( $p<0.05$ ) lower than that of control eggs. Hatching of the eggs incubated for 32 d ranged from 0 to only $14 \%$ (with the exception of 1 replicate, where it was $75 \%$ ), a significant reduction with respect to control eggs and eggs incubated for 1 and $4 \mathrm{~d}$.

Most of the eggs exposed to sulfide resumed hatching within $48 \mathrm{~h}$ of the transfer to normoxic seawater, but hatching was observed even after $10 \mathrm{~d}$. Incubation in sulfidic conditions for 1 or $4 \mathrm{~d}$ at both $\mathrm{pHs}$ did not significantly reduce the final hatching success (Fig. 1), which ranged from 75 to $100 \%$ after $1 \mathrm{~d}$ exposure and from 63 to $100 \%$ after 4 d. Sulfide-treated eggs also underwent a hatching decline with increase of the incubation time (Jonckheere-Terpstra trend test; $\mathrm{p}<$ 0.001). The hatching success of the eggs exposed to sulfide for $15 \mathrm{~d}$ at $\mathrm{pH} 8.2$ ranged from 20 to $88 \%$, and was significantly $(p<0.05)$ reduced with respect to control eggs and eggs treated for 1 and $4 \mathrm{~d}$. At pH 6.5, hatching success ranged from 0 to $88 \%$ and was significantly $(p<0.05)$ reduced only with respect to control eggs. When the exposure time was prolonged to $32 \mathrm{~d}$, hatching ranged from 20 to $80 \%$ in the eggs incubated at pH 8.2, while it was almost completely suppressed in the eggs incubated at $\mathrm{pH}$ 6.5. In both cases the reduction was significant with respect to control eggs and eggs treated for 1 and $4 \mathrm{~d}$.

Comparison of the different conditions (near anoxia, sulfide at $\mathrm{pH} 8.2$, sulfide at $\mathrm{pH}$ 6.5) showed that hatching success differed only among the eggs that had been incubated for $32 \mathrm{~d}$, the hatching of the eggs

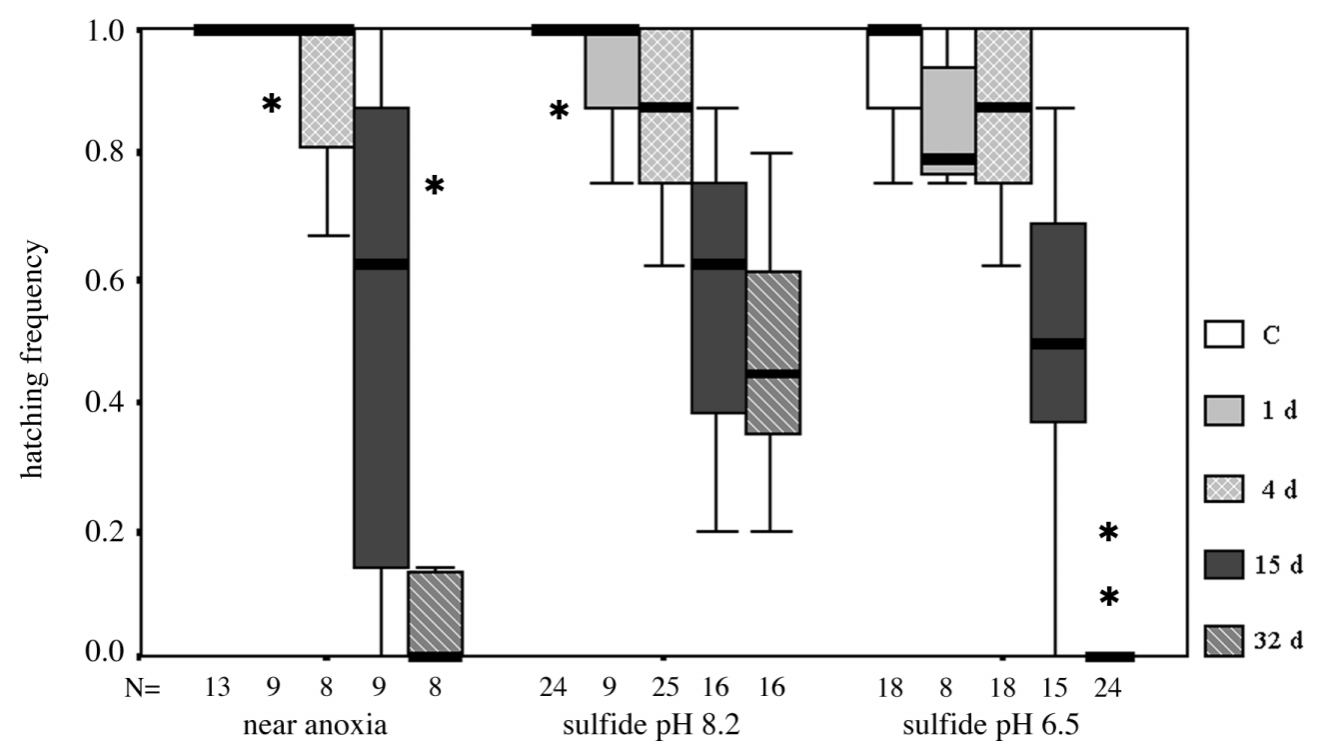

Fig. 1. Acartia tonsa. Boxand-whisker plots of hatching success (frequency) of eggs exposed to the different conditions. The line across each box indicates the median of the data, the top and bottom of each box are the 25th and 75th percentiles (quartiles), the vertical lines extending from the boxes indicate the data remaining outside. $\mathrm{C}=$ control (normoxic condition), $\mathrm{N}=$ number of replicates (vials), $*=$ outliers 
exposed to sulfide at $\mathrm{pH} 8.2$ being significantly $(\mathrm{p}<$ 0.05 ) higher than that of the eggs exposed to the other conditions. No significant difference was found between near anoxia and sulfide at $\mathrm{pH} 6.5$.

\section{Growth and survival}

In all the cohorts, the first nauplii generally developed to copepodites within 5 to $7 \mathrm{~d}$ after hatching and to adults within 10 to $12 \mathrm{~d}$, irrespective of egg treatment, exposure time and $\mathrm{pH}$. Longevity of adults ranged from 10 to $50 \mathrm{~d}$, being higher for females. Even though fecundity was not quantified, in all cohorts where individuals reached adulthood, eggs that hatched into nauplii were observed.

High variability in the percentages of nauplii that developed to copepodites and adults was observed in the control cohorts: 66 to $76 \%$ of the nauplii reached the copepodite stage and 39 to $56 \%$ reached adulthood. Consequently, when the impacts of the different treatments on survivorship and life expectancy were compared, only highly significant differences ( $p<$ 0.001) were accepted.

Survivorship of the copepods hatched from nearanoxia exposed eggs showed the same pattern as the control (Fig. 2). The percentages of nauplii that reached juvenile (from $50 \%$, after $32 \mathrm{~d}$ exposure, to $74 \%$, after $1 \mathrm{~d}$ exposure) and adult stages (from $32 \%$, after $15 \mathrm{~d}$ exposure, to $52 \%$, after $1 \mathrm{~d}$ exposure) were as high as those observed in control cohorts.

Incubation of eggs in sulfidic water for 1 or $4 \mathrm{~d}$ at both pHs did not affect subsequent survival, as shown by survivorship curves that were similar to those of the control cohort (Fig. 2). The percentages of nauplii that reached the copepodite stage ranged from $53 \%$ (after $4 \mathrm{~d}$ exposure at $\mathrm{pH}$ 6.5) to $69 \%$ (after $4 \mathrm{~d}$ exposure at $\mathrm{pH}$ 8.2). The percentages of nauplii that developed to adults varied from $36 \%$ (after $4 \mathrm{~d}$ exposure at $\mathrm{pH} 6.5$ ) to $59 \%$ (after $1 \mathrm{~d}$ exposure at $\mathrm{pH}$ 6.5). Exposure to sulfide for $15 \mathrm{~d}$ at $\mathrm{pH} 8.2$ caused a decline in survival of the hatched organisms: survival was significantly $(p<$ 0.001 ) reduced with respect not only to the control but also to the cohorts hatched from 1 and $4 \mathrm{~d}$ exposed eggs. Only $32 \%$ of the nauplii developed to copepodites and $18 \%$ became adults. Incubation of eggs at $\mathrm{pH} 6.5$, in contrast, did not affect survivorship. Survival showed the same pattern as the control and the percentage of nauplii that reached subsequent developmental stages was high: $46 \%$ of them became copepodites and $39 \%$ developed to the adult stage. Exposure to sulfidic conditions for $32 \mathrm{~d}$, at both $\mathrm{pHs}$, caused a significant $(p<0.001)$ reduction in survival of the hatched organisms. At pH 8.2, only $16 \%$ of the nauplii reached the copepodite and $12 \%$ the adult
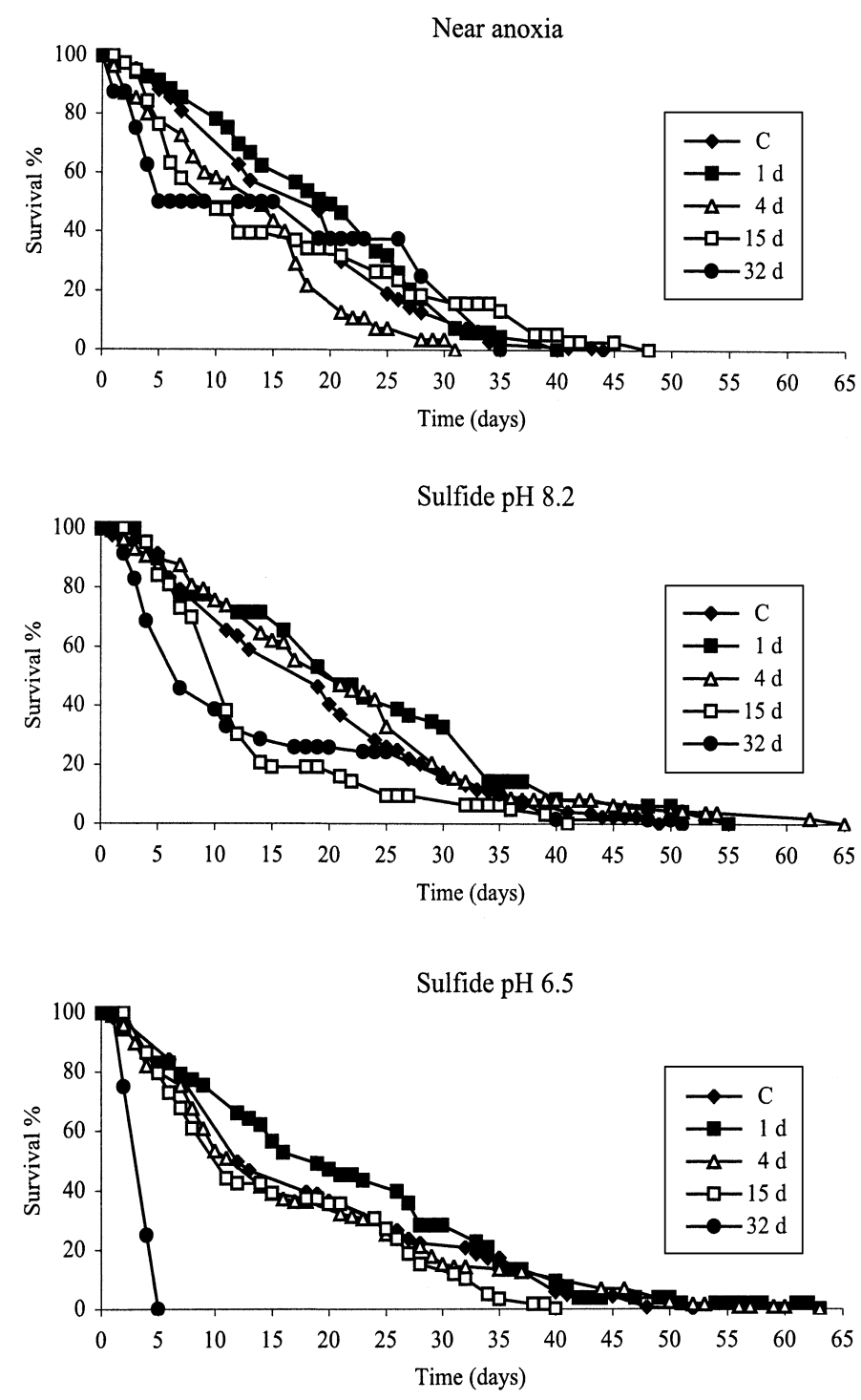

Fig. 2. Acartia tonsa. Survivorship pattern of the copepods hatched from eggs exposed to the different conditions. $\mathrm{C}=$ control (normoxic condition)

stage. When the eggs were incubated at $\mathrm{pH} 6.5$, the few hatched nauplii died within $4 \mathrm{~d}$ of the restoration of normoxic conditions and none reached the copepodite stage.

To assess the consequences of egg exposure to nearanoxic and sulfidic conditions for the entire life cycle of Acartia tonsa, data on hatching and on subsequent development and survival were compiled (Fig. 3) and life expectancies were compared (Table 1). Exposure of eggs to near anoxia or to sulfide at both $\mathrm{pHs}$ for 1 or $4 \mathrm{~d}$ did not reduce life expectancy: the survival curves over the course of the entire life cycle showed the same pattern as the control curves. Exposure of eggs to the different conditions for $15 \mathrm{~d}$ caused a significant $(\mathrm{p}<$ 
0.001) reduction in life expectancy with respect to control and to 1 and $4 \mathrm{~d}$ exposed cohorts. Life expectancy after exposure to sulfide at $\mathrm{pH} 8.2$ did not suffer a further reduction when exposure time was increased from 15 to $32 \mathrm{~d}$, whereas it was significantly reduced after exposure to sulfide at $\mathrm{pH} 6.5$ or to near anoxia. Comparison of the different conditions (near anoxia, sulfide at $\mathrm{pH}$ 8.2, sulfide at $\mathrm{pH}$ 6.5) (Table 2) showed significant differences in life expectancy only after incubation for $32 \mathrm{~d}$. Specimens exposed to sulfide at pH 6.5 were the most heavily impacted.
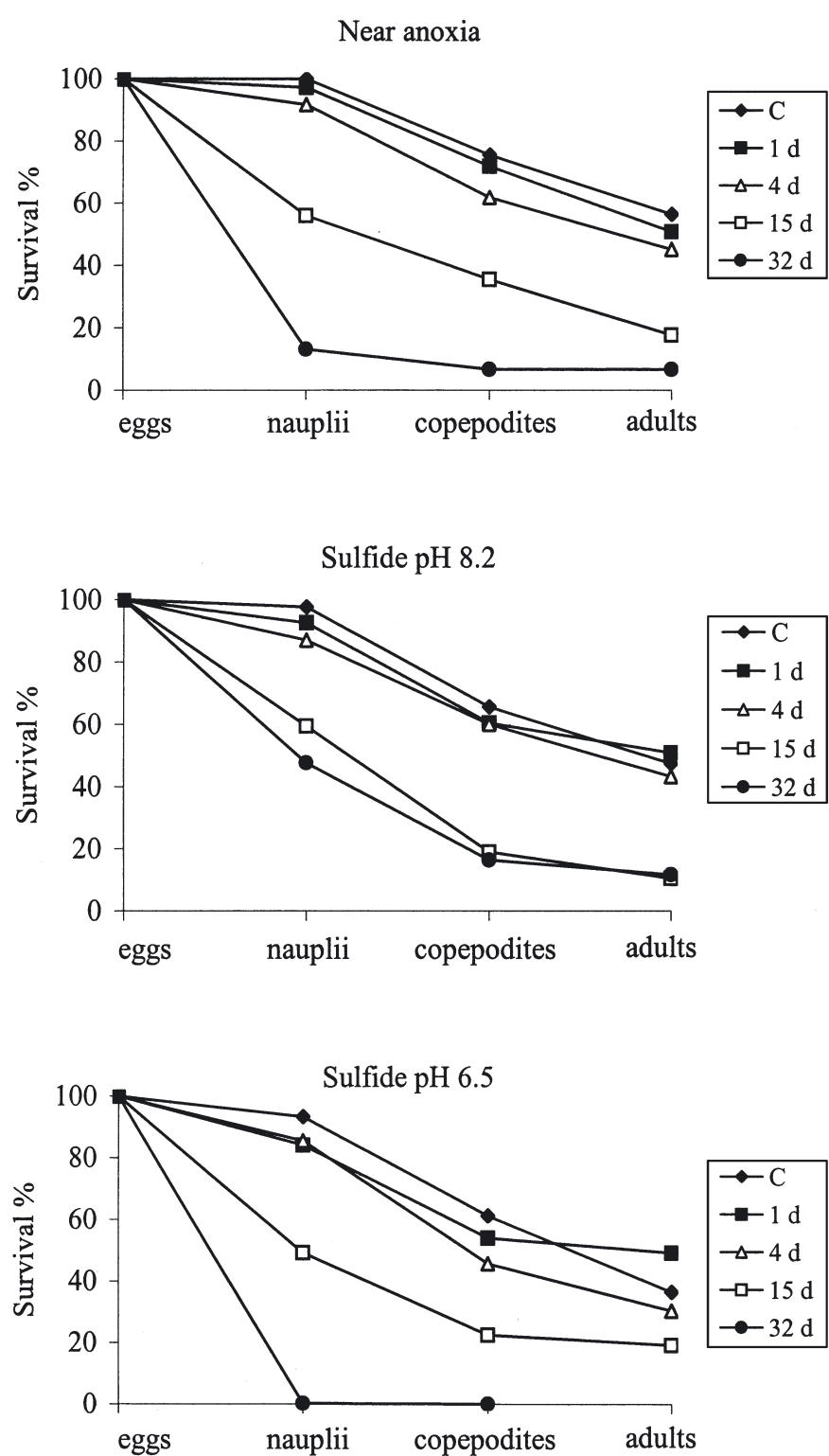

Fig. 3. Acartia tonsa. Survivorship at the different developmental stages (egg, larval, i.e. nauplius, juvenile, i.e. copepodite, and adult) after egg exposure to the different conditions. All the eggs were considered viable before treatments (100\% survival). $\mathrm{C}=$ control (normoxic condition)

\section{DISCUSSION}

Exposure to near anoxia (oxygen concentrations $1.78 \times 10^{-3}$ to $3.56 \times 10^{-3} \mathrm{mmol} \mathrm{l}^{-1}$ ) and sulfide at $\mathrm{pH} 8.2$ and $\mathrm{pH} 6.5$ induced quiescence in the eggs of Acartia tonsa: the eggs were able to resume hatching after restoration of normoxic conditions. However, in all the

Table 1. Wilcoxon (Gehan) nonparametric test: p-values obtained by comparing life expectancy after egg exposure to each condition for different times. $\mathrm{C}=$ control

\begin{tabular}{|lrrrr|}
\hline & \multicolumn{1}{c}{$\mathrm{C}$} & $1 \mathrm{~d}$ & $4 \mathrm{~d}$ & $15 \mathrm{~d}$ \\
\hline Near anoxia & & & & \\
$\mathrm{C}$ & & & & \\
$1 \mathrm{~d}$ & 0.412 & & & \\
$4 \mathrm{~d}$ & 0.050 & 0.271 & & \\
$15 \mathrm{~d}$ & $<0.001$ & $<0.001$ & $<0.001$ & \\
$32 \mathrm{~d}$ & $<0.001$ & $<0.001$ & $<0.001$ & $<0.001$ \\
Sulfide pH 8.2 & & & & \\
$\mathrm{C}$ & & & & \\
$1 \mathrm{~d}$ & 0.805 & & & \\
$4 \mathrm{~d}$ & 0.094 & 0.411 & & \\
$15 \mathrm{~d}$ & $<0.001$ & $<0.001$ & $<0.001$ & \\
$32 \mathrm{~d}$ & $<0.001$ & $<0.001$ & $<0.001$ & 0.090 \\
Sulfide pH 6.5 & & & & \\
$\mathrm{C}$ & & & & \\
$1 \mathrm{~d}$ & 0.959 & & & \\
$4 \mathrm{~d}$ & 0.014 & 0.137 & & \\
$15 \mathrm{~d}$ & $<0.001$ & $<0.001$ & $<0.001$ & \\
$32 \mathrm{~d}$ & $<0.001$ & $<0.001$ & $<0.001$ & $<0.001$ \\
\hline
\end{tabular}

Table 2. Wilcoxon (Gehan) nonparametric test: p-values obtained by comparing life expectancy after egg exposure to the different conditions for different times: (a) near anoxia versus sulfide at $\mathrm{pH} 8.2$ and sulfide at $\mathrm{pH} 6.5$; (b) sulfide at $\mathrm{pH} 8.2$ versus sulfide at $\mathrm{pH} 6.5$

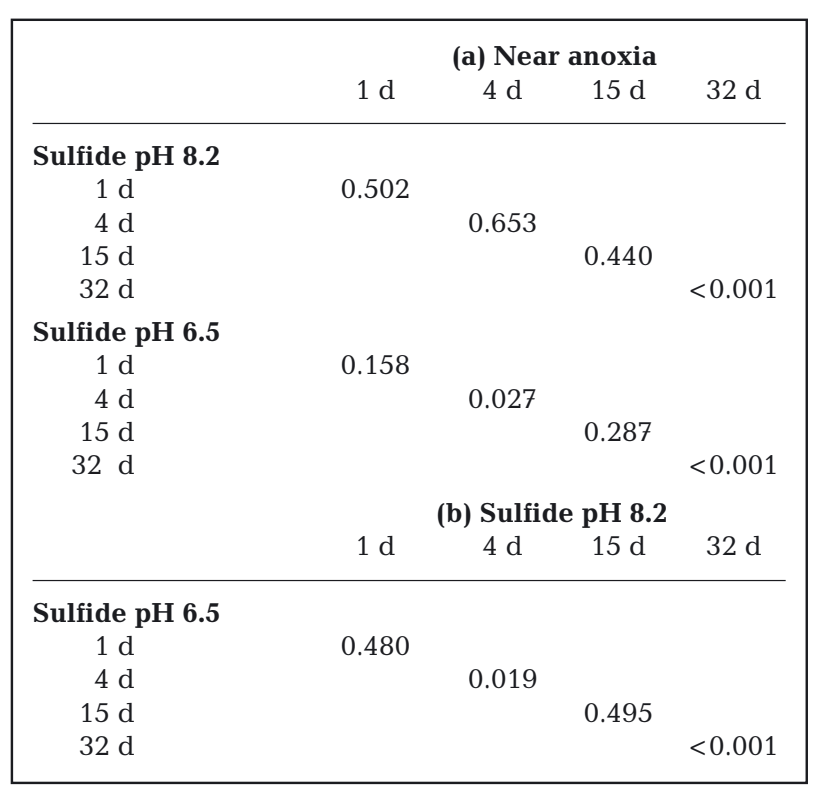


experimental conditions, egg viability decreased with increasing exposure time and, after 15 and $32 \mathrm{~d}$ incubation periods, significant declines in hatching were observed. The maximum survival times for the eggs exposed either to near anoxia or sulfide were not detectable, since after $32 \mathrm{~d}$ exposure some eggs were still viable in all the experimental conditions. Marcus \& Lutz (1994) and Marcus et al. (1997) found that the hatching success of $A$. tonsa eggs exposed to anoxia or anoxia/sulfide declined with increasing exposure time. Maximum survival times reported by Marcus \& Lutz (1994) for eggs exposed to anoxia were $28 \mathrm{~d}$ for 'newly spawned' eggs ( 0 to $3.5 \mathrm{~h}$ post-spawning) and $20 \mathrm{~d}$ for fully developed eggs (10 to $13.5 \mathrm{~h}$ post-spawning). Marcus et al. (1997) exposed newly spawned eggs to anoxia and anoxia/sulfide (at concentrations ranging from 0.283 to $0.352 \mathrm{mmol} \mathrm{l}^{-1}$ and $\mathrm{pH} 8.11$ to 8.67 ) and observed viable eggs after a $32 \mathrm{~d}$ incubation period for both conditions. The differences, according to Marcus \& Lutz (1994), were related to variations in the developmental stages of the eggs used in the experiments or, as reported by Marcus et al. (1997), 'may have been due to differences in the genetic and/or environmental histories of the females used to obtain eggs'. Both studies used females collected in the field (Gulf of Mexico) during different periods of the year and eggs at 2 stages of embryological development. Although we used females bred under standard conditions, so that environmental differences were minor and genetic variability would be presumably lower than in the field, and treated eggs ranging from 0 to $15 \mathrm{~h}$ old, our results are in the range of values reported by the cited studies. The differences in hatching success observed within each treatment appear consistent with the variability reported by Marcus \& Lutz (1994) and Marcus et al. (1997).

Comparison of the impacts of near anoxia and sulfide on viability of the eggs did not show significant differences when the exposure time was $\leq 15 \mathrm{~d}$. But when the incubation was prolonged to $32 \mathrm{~d}$, the hatching success of the eggs exposed to sulfide at $\mathrm{pH} 8.2$ was significantly higher than that of the eggs exposed to near anoxia. Lutz et al. (1994) suggest that 'perhaps prolonged exposure to low oxygen concentrations, as opposed to zero oxygen, is more detrimental to the eggs because, in the absence of oxygen, metabolism is shut down completely, whereas under low oxygen conditions some metabolic functions proceed'. Survival under anoxia depends on an overall reduction in metabolic rate to conserve substrates and reduce the accumulation of toxic end products, a phenomenon commonly referred to as 'metabolic rate depression' (Clegg 1997). Our results seem consistent with this. In our experiments, the addition of sulfide to near-anoxic water caused anoxia in the incubation vials. Under these conditions the metabolic rate depression is probably deeper than in near anoxia and cell poisoning is slowed down so that eggs can overcome longer exposure to stress conditions. It seems, therefore, that the hatching reduction observed after $32 \mathrm{~d}$ exposure was only due to the lack of oxygen, and that the exposure to sulfide at $\mathrm{pH} 8.2$ did not have additional negative effects on hatching success. These results appear to be consistent with the suggestions of Marcus et al. (1997): they reported no significant differences in viability for eggs from 3 calanoid copepod species (Acartia tonsa, Labidocera aestiva and Centropages hamatus) exposed to anoxia/sulfide (at $\mathrm{pH}$ values ranging from 8.11 to 8.67 ) and to anoxia alone, and suggested that the eggs which survived sulfide or prolonged exposure to anoxia had switched to anaerobic metabolism.

At $\mathrm{pH}$ 6.5, sulfide appeared to affect egg viability. Hatching was almost completely inhibited after $32 \mathrm{~d}$ exposure, showing significant differences with respect to $\mathrm{pH} 8.2$ and a reduction close to that observed in the eggs exposed to near anoxia alone. Metabolic rate depression and sulfide speciation may explain these different responses. The presence of sulfide brings the system (vial) to anoxia so that, according to Marcus et al. (1997) and Hagerman (1998), the eggs have to turn to anaerobic metabolism. The metabolic rate depression due to zero oxygen should presumably be the same at both pHs. All sulfide species can be considered toxic due to the equilibrium $\mathrm{H}_{2} \mathrm{~S} \leftrightarrow \mathrm{HS}^{-} \leftrightarrow \mathrm{S}^{2-}$ (Vismann 1996). However, it has been shown that total sulfide toxicity depends on $\mathrm{pH}$ (Broderius et al. 1977, Powell \& Somero 1986, Vismann 1996): at pH 6.5 the molecular $\mathrm{H}_{2} \mathrm{~S}$, which can penetrate into cells more readily than the anion $\mathrm{HS}^{-}$, represents more than $70 \%$ of total sulfide, whereas at $\mathrm{pH} 8.2$ the dominant species, present at more than $90 \%$, is $\mathrm{HS}^{-}$.

Studies of benthic invertebrates (Vismann 1990, De Zwaan et al. 1993, Cattani et al. 1996, Visman \& Hagerman 1996, Hagerman 1998) indicate that exposure to hypoxia/anoxia plus sulfide (at $\mathrm{pH} 8.0$ to 8.5 ) is more detrimental to the organisms than hypoxia or anoxia alone. Vismann \& Hagerman (1996) and Hagerman (1998) suggested that, when sulfide diffuses in biological systems, the metabolic rate cannot be drastically reduced since mechanisms of sulfide detoxification are probably needed even during anaerobiosis. Our results with copepod eggs contradict these studies. Sulfide exposure for $\leq 15 \mathrm{~d}$, even at the high concentrations we used, did not appear to be toxic to the Acartia tonsa eggs, irrespective of $\mathrm{pH}$. Sulfide toxicity became evident only after $32 \mathrm{~d}$ exposure at $\mathrm{pH} 6.5$, but even in this case the reduction in hatching success is not significantly different with respect to near anoxia alone. Bagarinao (1992) reported that there is no evidence that marine animals can exclude sulfide at the 
body wall. Due to the tissue diffusion coefficient of $\mathrm{H}_{2} \mathrm{~S}$, similar to that of $\mathrm{O}_{2}$ (Powell 1989), Vopel et al. (1998) suggested that the equilibrium between external and internal sulfide concentration in small-size organisms should be reached within a few hours. On the basis of these considerations, the different response to sulfide at $\mathrm{pH} 8.2$ and 6.5, detectable only after $32 \mathrm{~d}$ exposure, is not easy to explain. In this study we considered eggs instead of adult organisms: the presence of an egg wall able to block the entry of sulfide might explain the high tolerance of $A$. tonsa eggs. In this case, internal sulfide concentration should increase slowly, as a function of the exposure time and external molecular $\mathrm{H}_{2} \mathrm{~S}$ concentration; only when the eggs are exposed for a long time to high concentrations of $\mathrm{H}_{2} \mathrm{~S}$, can the internal sulfide reach such a level where toxic effects are observed.

Growth and survival of hatched organisms were not affected when eggs were exposed to the different experimental conditions for short times (1 and $4 \mathrm{~d}$ ). As for hatching, the most considerable differences in the effects of near anoxia and sulfide at different $\mathrm{pH}$ were observed after $32 \mathrm{~d}$ exposure: incubation in near anoxia did not affect the survival of the organisms hatched from the exposed eggs, exposure to sulfide at $\mathrm{pH} 8.2$ caused a significant decline with respect to the control, and exposure to sulfide at $\mathrm{pH} 6.5$ brought about the death at the naupliar stage of the few hatched organisms. Differences in the accumulation of toxic end products (e.g. lactate) during quiescence or sublethal toxic effects of sulfide may explain these responses. It may be that in near-anoxic conditions selection occurs at the egg stage: the few eggs that survive probably have the highest tolerance and are able to develop to adult stage. In sulfidic conditions, toxic end product accumulation is presumably lower and reaches a sublethal level. Consequently, hatching success is higher than in near anoxia but many nauplii may be not able to grow and develop. Besides, a toxic effect of sulfide cannot be excluded: after $32 \mathrm{~d}$ exposure at $\mathrm{pH} 8.2$ the internal sulfide concentration may reach a sublethal level affecting the growth and survival of nauplii. At pH 6.5, internal sulfide probably reaches a level where hatching success is near zero.

The highest variability in hatching data was observed after $15 \mathrm{~d}$ exposure. In all conditions the hatching median values were near $50 \%$, a value around which quantal data generally have the highest variability. Moreover, exposure of the eggs to near anoxia and to sulfide at $\mathrm{pH} 6.5$ for $15 \mathrm{~d}$ did not seem to affect growth and survival of the nauplii, whereas incubation in sulfidic conditions at $\mathrm{pH} 8.2$ caused a decline with respect to the control and to 1 and $4 \mathrm{~d}$ (short-time) exposure. However, comparison of the various conditions did not show significant differences among the survival curves of the copepods hatched from eggs exposed for $15 \mathrm{~d}$. These results cannot be easily explained. It could be that differences in responses to the various experimental conditions become noticeable only when the ability to withstand the cost of quiescence is severely reduced. The $15 \mathrm{~d}$ period might be a threshold time, during which adaptation mechanisms to overcome exposure to near anoxia and sulfide become close to exhaustion. At this exposure time, even minor variations in experimental conditions (i.e. oxygen concentration, genetic variability, age of the eggs) could bring about a high variability in the responses. Furthermore, the small sample size could have had an effect.

When hatching success and subsequent growth and survival are considered together, the consequences of egg exposure to near anoxia or sulfide for the entire life cycle and, hence, possible effects on the population dynamics of Acartia tonsa are more appreciable. Exposure times $\geq 15 \mathrm{~d}$ caused a strong reduction in life expectancy. Thus, when the eggs of $A$. tonsa experience near-anoxic or sulfidic conditions for a long time, the population dynamics of this species will be adversely affected. When exposure time was increased from 15 to $32 \mathrm{~d}$, the effects on life expectancy differed depending on the different conditions experienced by the eggs. The eggs exposed to sulfide at $\mathrm{pH} 8.2$ did not suffer a further decrease in life expectancy, whereas the eggs exposed to near anoxia or sulfide at $\mathrm{pH} 6.5$ underwent a severe reduction. In particular, exposure at pH 6.5 completely hindered survival.

Our study indicates that long-time exposure of eggs to near anoxia is more detrimental than exposure to high sulfide concentrations, when $\mathrm{pH}$ is in the range of natural seawater (7.9 to 8.3) and the dominant sulfide species is $\mathrm{HS}^{-}$. On the contrary, when exposure to sulfide is at a $\mathrm{pH}$ as low as the values that can be reached in pore waters (6.0 to 6.5) and the species $\mathrm{H}_{2} \mathrm{~S}$ prevails, the effects on organisms are more detrimental than in near anoxia alone.

Acartia tonsa is a species typical of eutrophic coastal areas (Brylinsky 1981). It was recorded for the first time in the Mediterranean Sea by Gaudy \& Viñas (1985) and in the Adriatic Sea by Farabegoli et al. (1989). In recent years it has become the dominant species of the planktonic copepod component in the North Adriatic lagoons. The greater numerical importance of $A$. tonsa led to the progressive disappearance of the congeneric species A. margalefi and A. latisetosa, which were typical of the most confined areas of these lagoons (Sei et al. 1996). The high tolerance to both near anoxia and sulfide shown by the eggs of $A$. tonsa could favor its strong development in the lagoons to the detriment of congeneric species. Differences in tolerance to anoxia between $A$. tonsa and A. clausi eggs has been sug- 
gested by Gaudy et al. (2000) as a possible factor explaining the absence of an A. clausi population in the Berre lagoon (French Mediterranean coast), where A. tonsa is the dominant species. The comparative evaluation of the tolerance of the Acartia species eggs to anoxia and anoxia/sulfide could allow better understanding of the role played by these stress factors in the distribution of these species in coastal environments.

Acknowledgements. We thank V. Nervegna, F. Armeli and N. Imperatore for their assistance in the laboratory and Professor L. Soliani for statistical advice. We also thank technical staff of the Stazione idrologica dell'Università di Padova (Chioggia, Venice) for their assistance during sampling. This research (Eloise number 456/22) was partially supported by EC contract no. ENV4-CT6-218 and by the Italian Ministero dell'Università e della Ricerca Scientifica (COFIN 99).

\section{LITERATURE CITED}

Ambler JW (1985) Seasonal factors affecting egg production and viability of eggs of Acartia tonsa Dana from East Lagoon, Galveston, Texas. Est Coast Shelf Sci 20:743-760

APHA, AWWA, WPCF (1989) Standard methods for the examination of water and wastewater, 17th edn. APHA, Washington, DC

Bagarinao T (1992) Sulfide as an environmental factor and toxicant: tolerance and adaptations in aquatic organisms. Aquat Toxicol 24:21-62

Bartoli M, Barbanti A, Castaldelli G, Giordani G, Viaroli P (1996) Microprofiling as a tool to analyse sediment-water interactions. Atti VII Congr SItE, Napoli. Atti SItE 17: 539-542 (in Italian with English abstract)

Broderius SJ, Smith LL Jr, Lind DT (1977) Relative toxicity of free cyanide and dissolved sulfide forms to the fathead minnow Pimephales promelas. J Fish Res Board Can 34: 2323-2332

Brylinski JM (1981) Report on the presence of Acartia tonsa Dana (Copepoda) in the harbour of Dunkirk (France) and its geographical distribution in Europe. J Plankton Res 3: $255-260$

Cattani O, Isani G, Carpenè E, De Zwaan A, Vitali G, Cortesi P (1996) Effetti dell'anossia e dell'idrogeno solforato su Squilla mantis L. (Crustacea, Stomatopoda). Biol Mar Medit 3:442-443

Clegg JS (1997) Embryos of Artemia franciscana survive four years of continuous anoxia: the case for complete metabolic rate depression. J Exp Biol 200:467-475

Cline JD (1969) Spectrophotometric determination of hydrogen sulfide in natural waters. Limnol Oceanogr 14: 454-459.

De Zwaan A, Cattani O, Putzer VM (1993) Sulfide and cyanide induced mortality and anaerobic metabolism in the arcid blood clam Scapharca inaequivalvis. Comp Biochem Physiol C, 105:49-54

Diaz RJ (2001) Overview of hypoxia around the world. J Environ Qual 30:275-281

Diaz RJ, Rosenberg R (1995) Marine benthic hypoxia: a review of its ecological effects and the behavioural responses of benthic macrofauna. Oceanogr Mar Biol Annu Rev 33:245-303

Dunn OJ (1964) Multiple comparisons using rank sums. Technometrics 6:241-52
Farabegoli A, Ferrari I, Manzoni C, Pugnetti A (1989) Prima segnalazione nel Mare Adriatico del copepode calanoide Acartia tonsa Dana. Nova Thalassia 10:207-208

Gamenick I, Jahn A, Vopel K, Giere O (1996) Hypoxia and sulphide as structuring factors in a macrozoobenthic community on the Baltic Sea shore: colonisation studies and tolerance experiments. Mar Ecol Prog Ser 144:73-85

Gaudy R, Viñas MD (1985) Première signalisation en Mediterranée du copépode pélagique Acartia tonsa. Rapp Comm Int Mer Médit 29:227-229

Gaudy R, Cervetto G, Pagano M (2000) Comparison of the metabolism of Acartia clausi and A. tonsa: influence of temperature and salinity. J Exp Mar Biol Ecol 247:51-65

Giordani G, Bartoli M, Cattadori M, Viaroli P (1996) Sulphide release from anoxic sediments in relation to iron availability and organic matter recalcitrance and its effects on inorganic phosphorus recycling. Hydrobiologia 329:211-222

Hagerman L (1998) Physiological flexibility; a necessity for life in anoxic and sulphidic habitats. Hydrobiologia 375/376:241-254

Lutz RV, Marcus NH, Chanton JP (1992) Effects of low oxygen concentrations on the hatching and viability of eggs of marine calanoid copepods. Mar Biol 114:241-247

Lutz RV, Marcus NH, Chanton JP (1994) Hatching and viability of copepod eggs at two stages of embryological development: anoxic/hypoxic effect. Mar Biol 119:199-204

Marcus NH, Boero F (1998) Minireview: the importance of benthic-pelagic coupling and the forgotten role of life cycles in coastal aquatic systems. Limnol Oceanogr 43: 763-768

Marcus NH, Lutz RV (1994) Effects of anoxia on the viability of subitaneous eggs of planktonic copepods. Mar Biol 121: 83-87

Marcus NH, Lutz RV, Chanton JP (1997) Impact of anoxia and sulfide on the viability of eggs of three planktonic copepods. Mar Ecol Prog Ser 146:291-295

Mor E, Beccaria AM (1971) Determinazione dell'ossigeno disciolto in acqua marina in presenza di solfuri. Ann Chim 61: 363-371

Nilsson H, Rosenberg R (1994) Hypoxic response of two marine benthic communities. Mar Ecol Prog Ser 115:209-217

Nixon SW 1(995) Coastal marine eutrophication: a definition, social causes, and future concerns. Ophelia 41:199-219

Paerl HW (1997) Coastal eutrophication and harmful algal blooms: importance of atmospheric deposition and groundwater as 'new' nitrogen and other sources. Limnol Oceanogr 42:1154-1165

Pihl L, Baden SP, Diaz RJ (1991) Effects of periodic hypoxia on distribution of demersal fish and crustaceans. Mar Biol 108:349-360

Powell E (1989) Oxygen, sulfide and diffusion: why thiobiotic meiofauna must be sulfide-insensitive first-order respirers. J Mar Res 47:887-932

Powell MA, Somero GN (1986) Hydrogen sulfide oxidation is coupled to oxidative phosphorylation in mitochondria of Solemya reidi. Science 233:563-566

Rabalais NN, Turner RE (2001) Coastal hypoxia: consequences for living resources and ecosystems. Coastal and Estuarine Studies 58. American Geophysical Union, Washington, DC

Roman MR, Gauzens AL, Rhinehart WK, White JR (1993) Effects of low oxygen waters on Chesapeake Bay zooplankton. Limnol Oceanogr 38:1603-1614

Sei S, Rossetti G, Villa F, Ferrari I (1996) Zooplankton variability related to environmental changes in a eutrophic coastal lagoon in the Po Delta. Hydrobiologia 329:45-55

Stalder LC, Marcus NH (1997) Zooplankton responses to 
hypoxia: behavioural patterns and survival of three species of calanoid copepods. Mar Biol 127:599-607

Uye S, Fleminger A (1976) Effects of various environmental factors on egg development of several species of Acartia in southern California. Mar Biol 38:253-262

Vismann B (1990) Sulfide detoxification and tolerance in Nereis (Hediste) diversicolor and Nereis (Neanthes) virens (Anellida: Polychaeta). Mar Ecol Prog Ser 59:229-238

Vismann B (1996) Sulfide species and total sulfide toxicity in the shrimp Crangon crangon. J Exp Mar Biol Ecol 204:141-154

Vismann B, Hagerman L (1996) Recovery from hypoxia with and without sulphide in Saduria entomon: oxygen debt,

Editorial responsibility: Otto Kinne (Editor),

Oldendorf/Luhe, Germany reduced sulfur and anaerobic metabolites. Mar Ecol Prog Ser 143:131-139

Vistisen B, Vismann B (1997) Tolerance to low oxygen and sulfide in Amphiura filiformis and Ophiura albida (Echinodermata: Ophiuroidea). Mar Biol 128:241-246

Vopel K, Dehmlow J, Johansson M, Günter A (1998) Effects of anoxia and sulphide on populations of Cletocamptus confluens (Copepoda, Harpacticoida). Mar Ecol Prog Ser 175: 121-128

Wang F, Chapman PM (1999) Biological implications of sulfide in sediment-a review focusing on sediment toxicity. Environ Toxicol Chem 18:2526-2532

Submitted: January 21, 2004; Accepted: April 20, 2004

Proofs received from author(s): July 16, 2004 